\title{
Effect on deformation process of adding a copper core to multifilament MgB2 superconducting wire
}

\author{
Hancock, Michael Halloway; Bay, Niels
}

Published in:

I E E E Transactions on Applied Superconductivity

Link to article, DOI:

10.1109/TASC.2007.899059

Publication date:

2007

Document Version

Publisher's PDF, also known as Version of record

Link back to DTU Orbit

Citation (APA):

Hancock, M. H., \& Bay, N. (2007). Effect on deformation process of adding a copper core to multifilament MgB2 superconducting wire. I E E E Transactions on Applied Superconductivity, 17(2), 3054-3058.

https://doi.org/10.1109/TASC.2007.899059

\section{General rights}

Copyright and moral rights for the publications made accessible in the public portal are retained by the authors and/or other copyright owners and it is a condition of accessing publications that users recognise and abide by the legal requirements associated with these rights.

- Users may download and print one copy of any publication from the public portal for the purpose of private study or research.

- You may not further distribute the material or use it for any profit-making activity or commercial gain

- You may freely distribute the URL identifying the publication in the public portal

If you believe that this document breaches copyright please contact us providing details, and we will remove access to the work immediately and investigate your claim. 


\title{
Effect on Deformation Process of Adding a Copper Core to Multifilament $\mathrm{MgB}_{2}$ Superconducting Wire
}

\author{
M. H. Hancock and N. Bay
}

\begin{abstract}
Using the PIT method, multifilament wire with different packing strategies has been manufactured. In all, three types of wire have been investigated, a 19-filament configuration using ex-situ powder in an Fe-matrix and two 8-filament configurations in an Fe-matrix applying a copper core, one using in-situ and another using ex-situ powder. The effect on the annealing requirements during mechanical processing of adding such a copper core has been investigated. The results show that the number of required annealings drops by about a factor of one half with the addition of a copper core. This finding is supported by numerical simulations of the deformation process which indicate that tensile stresses are concentrated around the middle of the wire during the drawing process. As such, strategic packing of the multifilament configuration can reduce the need for annealing during the mechanical deformation process. It is also found that the multifilament configuration using in-situ powder requires less annealing than the ex-situ counterpart. This is most likely due to the fact that in-situ powder is more readily compacted than ex-situ powder.
\end{abstract}

Index Terms-Magnesium diboride, superconducting composites, superconducting filaments and wires, superconducting materials mechanical factors.

\section{INTRODUCTION}

A NUMBER of different research groups now successfully manufacture $\mathrm{MgB}_{2}$ wires using the PIT method [1]-[12]. Two general approaches to using the PIT method exist: ex-situ [1]-[4] and in-situ [6], [11], and [12]. These two methods each have their advantages and disadvantages [13]. The effect on thermal and electrical stabilization of adding a copper core to a superconducting multifilament $\mathrm{MgB}_{2}$ wire is well documented [14], whereas this paper examines the possible added befits on mechanical properties, which may be obtained by adding such a copper core.

When manufacturing $\mathrm{MgB}_{2}$ wire, it is generally not desirable to perform annealing between steps in the deformation process. There are two main reasons for this. Firstly, softening of the matrix material leads to less compaction of the powder and a less homogenous boundary between powder and tube. Secondly, for some matrix materials, as for example iron, the annealing temperature is close to or above the temperature where the powder starts to react.

Manuscript received August 17, 2006. This work was supported by the Danish Technical Research Council under the Framework Program on Superconductivity.

The authors are with the Department of Manufacturing Engineering and Management, Danish Technical University, 2800 Lyngby, Denmark (e-mail: mhh@ipl.dtu.dk; nbay@ipl.dtu.dk).

Color versions of one or more of the figures in this paper are available online at http://ieeexplore.ieee.org.

Digital Object Identifier 10.1109/TASC.2007.899059
For single-filament wire with an iron matrix, drawing can normally be performed without annealing as long as the overall reduction is kept moderate. This would typically mean an initial tube diameter of 8 to $10 \mathrm{~mm}$ and a final wire of approximately $1 \mathrm{~mm}$. However, drawing multifilament wire without annealing becomes practically impossible if the multifilament is comprised of already strain hardened single-filaments, due to iron's mechanical properties [15]. In such cases, it is important to establish the minimum annealing required.

This paper examines which differences there are in annealing requirements for multifilament wires with and without a copper core. Investigations are made into the mechanisms involved with fracture and an optimized annealing schedule is proposed for both wire types.

\section{EXPERIMENTAL DETAILS}

Two different multifilament packing strategies were used, one consisting of 19 filaments and the other consisting of 8 filaments with a copper core.

Both in-situ and ex-situ powder was used in two different 8-filament wires, whereas only ex-situ powder was used for the 19-filament configuration. The ex-situ powder was delivered by Alfa Aesar (325 mesh and 99.8\% pure). The in-situ powder consisted of Mg powder delivered by Alfa Aesar (325 mesh and $99.8 \%$ pure) and amorphous boron (95-97\% pure).

The single-filament used in all cases was manufactured using the powder in tube method. An annealed iron tube (99.9\% pure) with an outer diameter of $10 \mathrm{~mm}$ and a wall thickness of $1.5 \mathrm{~mm}$ was filled with powder which was pre-compacted manually with a rod. Subsequently, the tube was reduced to wire by drawing using a constant area reduction between drawing steps of $10 \%$ and a semi-die angle of $7^{\circ}$. The final diameter of the singlefilament wire was $1.86 \mathrm{~mm}$ for use in the 8-filament wire and $1.62 \mathrm{~mm}$ for use in the 19-filament wire. For the center of the 8 -filament wire, a copper filament (99.95\% pure) was drawn to a diameter of $3.00 \mathrm{~mm}$ and then subsequently annealed.

A schematic cross section of the initial configuration of the 8- and 19-filament wires can be seen in Fig. 1. In all cases the outer tube consisted of an annealed iron tube (99.9\% pure) with an outer diameter of $10 \mathrm{~mm}$ and a wall thickness of $1.5 \mathrm{~mm}$. To seal the ends of the tubes a copper cylinder and a threaded cap of mild steel was applied. After the first drawing operation, the copper cylinder was sealed within the tube and the threaded cap could be cut away. All multifilament wire was drawn using a constant area reduction between drawing steps of $10 \%$ and a semi-die angle of $7^{\circ}$ to a final diameter of $1.36 \mathrm{~mm}$.

Different annealing schedules between drawing steps were examined for the two different packing configurations. For the 8-filament configuration, 5 different strategies were tested 


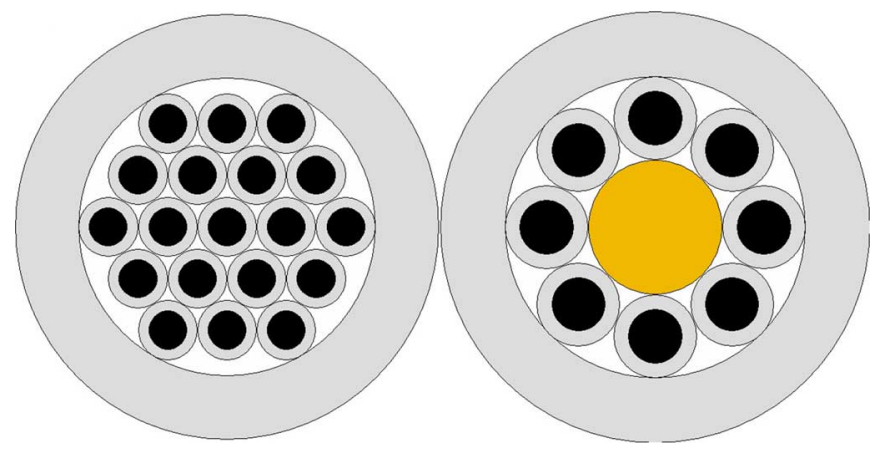

Fig. 1. Schematic of initial multifilament packing configurations.

TABLE I

Results of Drawing 8-Fillament EX-Situ WiRE

\begin{tabular}{|c|c|c|c|c|c|}
\hline Diameter at & \multicolumn{6}{|c|}{ Specimen } \\
\cline { 2 - 6 } annealing & a & b & c & d & e \\
\hline $10.00 \mathrm{~mm}$ & $\mathbf{X}$ & $\mathbf{X}$ & $\mathbf{X}$ & $\mathbf{X}$ & \\
\hline $5.00 \mathrm{~mm}$ & $\mathbf{X}$ & $\mathbf{X}$ & & & \\
\hline $3.50 \mathrm{~mm}$ & $\mathbf{X}$ & & $\mathbf{X}$ & & \\
\hline $2.56 \mathrm{~mm}$ & $\mathbf{X}$ & $\mathbf{X}$ & & & \\
\hline $\begin{array}{l}\text { Diameter at } \\
\text { fracture } \\
{[\mathrm{mm}]}\end{array}$ & None & None & None & 1.44 & 8.17 \\
\hline
\end{tabular}

TABLE II

RESULTS OF DRAWING 8-FILAMENT IN-SitU WIRE

\begin{tabular}{|c|c|c|c|c|c|}
\hline \multirow{2}{*}{$\begin{array}{c}\text { Diameter at } \\
\text { annealing }\end{array}$} & \multicolumn{5}{|c|}{ Specimen } \\
\hline & $\mathrm{f}$ & $\mathrm{g}$ & $\mathrm{h}$ & $\mathrm{i}$ & $\mathrm{j}$ \\
\hline $10.00 \mathrm{~mm}$ & $\mathbf{X}$ & $\mathbf{X}$ & $\mathbf{X}$ & $\mathbf{X}$ & \\
\hline $5.00 \mathrm{~mm}$ & $\mathbf{x}$ & $\mathbf{x}$ & & & \\
\hline $3.50 \mathrm{~mm}$ & $\mathbf{X}$ & & $\mathbf{X}$ & & \\
\hline $2.56 \mathrm{~mm}$ & $\mathbf{X}$ & $\mathbf{X}$ & & & \\
\hline $\begin{array}{l}\text { Diameter at } \\
\text { fracture } \\
{[\mathrm{mm}]}\end{array}$ & None & None & None & None & 7.75 \\
\hline
\end{tabular}

TABLE III

RESUlTS OF DRAWING 19-FILAMENT EX-SITU WIRE

\begin{tabular}{|r|c|c|c|c|c|c|}
\hline Diameter at & \multicolumn{7}{|c|}{ Specimen } \\
\cline { 2 - 7 } annealing & $\mathrm{k}$ & $\mathrm{l}$ & $\mathrm{m}$ & $\mathrm{n}$ & $\mathrm{o}$ & $\mathrm{p}$ \\
\hline $10.00 \mathrm{~mm}$ & $\mathbf{X}$ & $\mathbf{x}$ & $\mathbf{x}$ & $\mathbf{x}$ & $\mathbf{x}$ & \\
\hline $6.62 \mathrm{~mm}$ & $\mathbf{X}$ & & $\mathbf{x}$ & & & \\
\hline $4.34 \mathrm{~mm}$ & $\mathbf{X}$ & $\mathbf{x}$ & $\mathbf{x}$ & $\mathbf{x}$ & & \\
\hline $3.00 \mathrm{~mm}$ & $\mathbf{X}$ & $\mathbf{X}$ & & & & \\
\hline $1.97 \mathrm{~mm}$ & $\mathbf{x}$ & $\mathbf{x}$ & $\mathbf{x}$ & & & \\
\hline $\begin{array}{l}\text { Diameter at } \\
\text { fracture } \\
{[\mathrm{mm}]}\end{array}$ & None & None & 1.97 & 3.00 & 4.12 & 8.19 \\
\hline
\end{tabular}

ranging from no annealing to annealing for every 50\%-75\% reduction, see Tables I and II. For the 19-filament configuration, 6 different annealing strategies were tested ranging from no annealing to annealing for every $56 \%$ reduction, see Table III.

All annealing steps were performed at $550^{\circ} \mathrm{C}$ for the duration of one hour. This temperature was chosen based on the data seen in Fig. 2 with the purpose of not overly softening the matrix material or reaching temperatures where a reaction occurs in the powder.

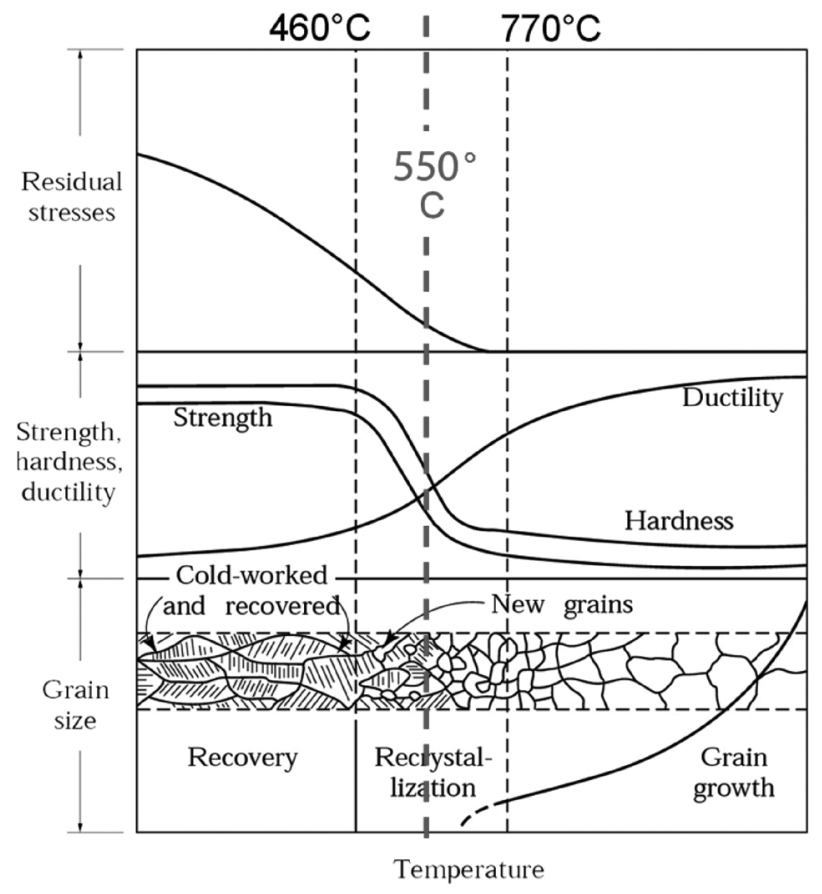

Fig. 2. Influence of temperature on annealing of iron [16].

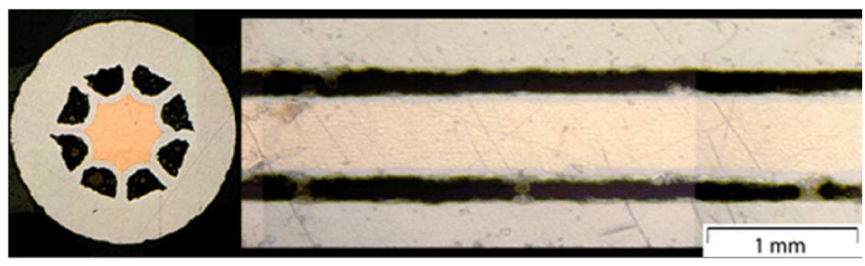

Fig. 3. Specimen "c", 8-filament wire with copper core using ex-situ powder, annealed twice.

\section{EXPERIMENTAL RESULTS}

Tables I, Tables II, Tables III show the result of drawing the 16 samples with varying annealing schedules and multifilament configuration. It is clear that the 19-filament wire is most susceptible to fracture, requiring intermediate annealing at least 4 times. The 8-filament ex-situ wire required annealing twice, whereas the 8-filament in-situ wire required annealing only once.

Images of specimens "c", "i", "l", and "n" can be seen in Figs. 3 to 6 . It is seen that the interface between the powder and matrix material has a more regular geometry for the in-situ powder, than for the ex-situ powder. This is expected to be caused by the fact that in-situ powder is much more readily compacted than ex-situ powder.

\section{Finite Element Analysis}

As a means to understand the mechanisms involved in the drawing process, finite element models of the process were made. The models were made in the commercially available code "ELFEN" using an explicit solver and the capped Drucker-Prager material model for the powder. All simulations were for ex-situ powder using data obtained using the "Powder 


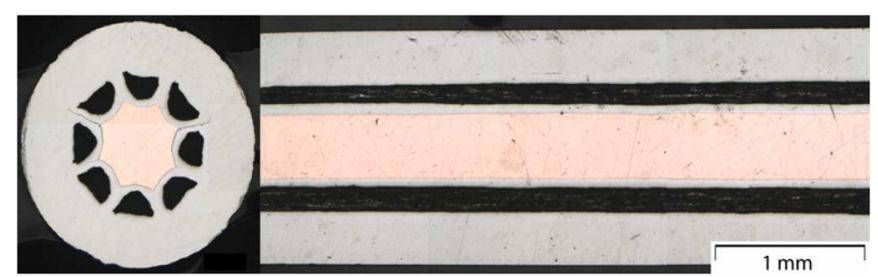

Fig. 4. Specimen "i”, 8-filament wire with copper core using in-situ powder, annealed once.

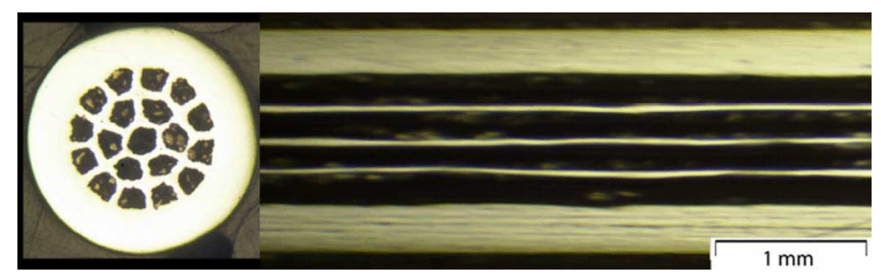

Fig. 5. Specimen "l", 19-filament wire using ex-situ powder, annealed four times.

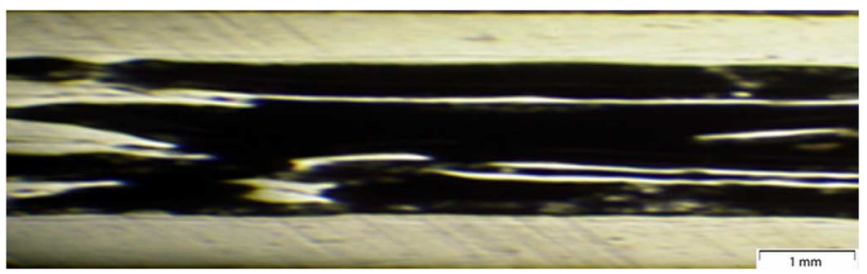

Fig. 6. Specimen "n", 19-filament wire using ex-situ powder, annealed twice, showing internal filament fracture.

in Flexible Die Test", or PFD-test [17]. The following values were used for the Drucker-Prager model:

Friction slope, $\eta: 0.779$

Dilatancy slope, $\xi: 0,866$

Tensile strength, $\mathrm{p}_{\mathrm{t}}: 25.3 \mathrm{MPa}$

Hydrostatic yield stress: $\mathrm{p}_{\mathrm{c}}=0.566 \mathrm{e}^{17.489 \varepsilon}[\mathrm{MPa}]$, where $\varepsilon$ is the volumetric plastic strain.

Material data for the plastic behavior at large strains in copper and iron were obtained through experiments involving pre-straining of samples by drawing to different reductions and subsequent tensile testing. The following stress-strain curves were obtained:

$$
\begin{aligned}
& \sigma_{C u}=371 \varepsilon^{0.099} \quad[M P a] \\
& \sigma_{F e}=620 \varepsilon^{0.313} \quad[M P a]
\end{aligned}
$$

To save simulation time the models were made in $2 \mathrm{D}$; to achieve this, an approximation had to be made regarding the models geometry. As seen in Fig. 7, axis-symmetrical models are adopted for the two packing strategies, where matrix and powder material is distributed in concentric rings. The material is distributed such that the volumes of the matrix material and powder in the model correspond to the true volumes in the multifilament. Due to the approximation in geometry a small error is expected to be present in the region where the powder is located. However, it is assumed that this error has a negligible influence on the evaluation of the axial stresses, which are of interest in the present work.
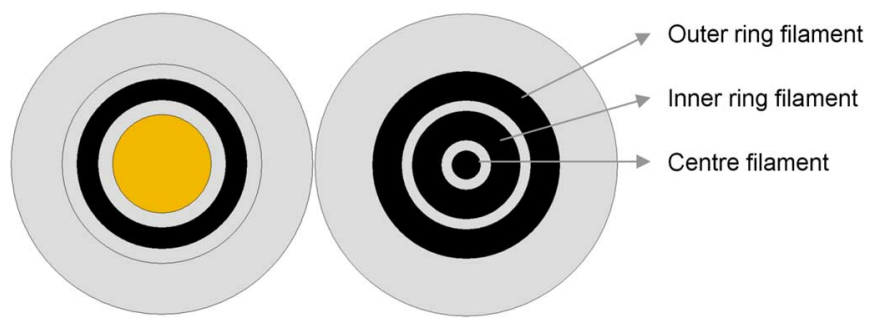

Fig. 7. Approximation of powder distribution for 2D FEM simulation.

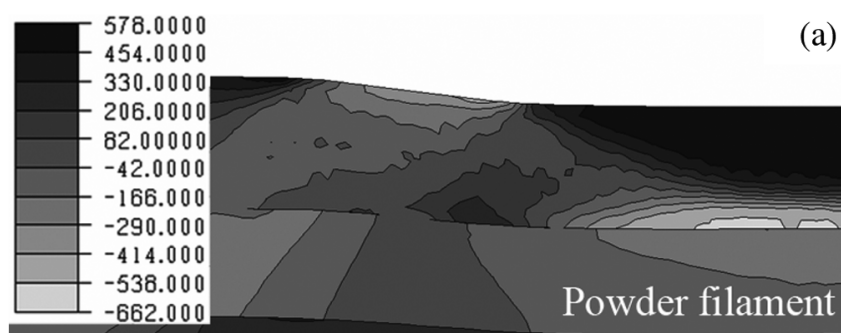

Copper filament

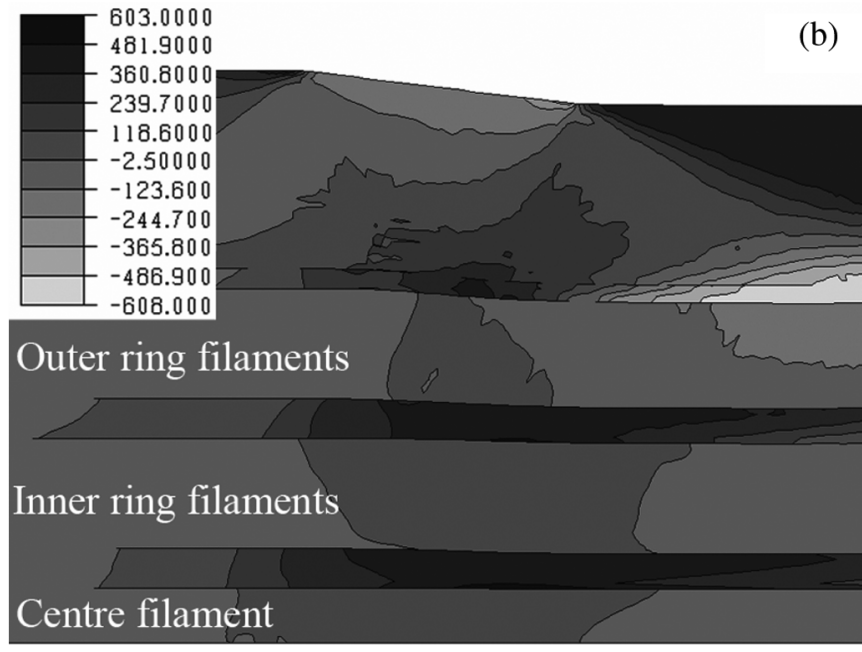

Fig. 8. Longitudinal section of axial stress (MPa) in multifilament wire during drawing: ((a) 8-filament wire with copper core; (b) 19-filament wire).

The data from the finite element models of the 19-filament wire and the 8-filament wire have been compared. All simulations were carried out using pre-straining level corresponding to the final drawing step, without any intermediate annealing. Fig. 8 shows the overall distribution of axial stress for the two multifilament configurations. Since it is tensile stress in the axial direction which induces fracture in the wire, this has been examined more closely for two critical components of the wire, namely the powder and the matrix material of the single-filaments used. Since the powder can only carry a very negligible amount of tensile stress [17] it is essential to keep this stress level as low as possible. The matrix material in the single-filament tubes is critical since this metal is already strain hardened 

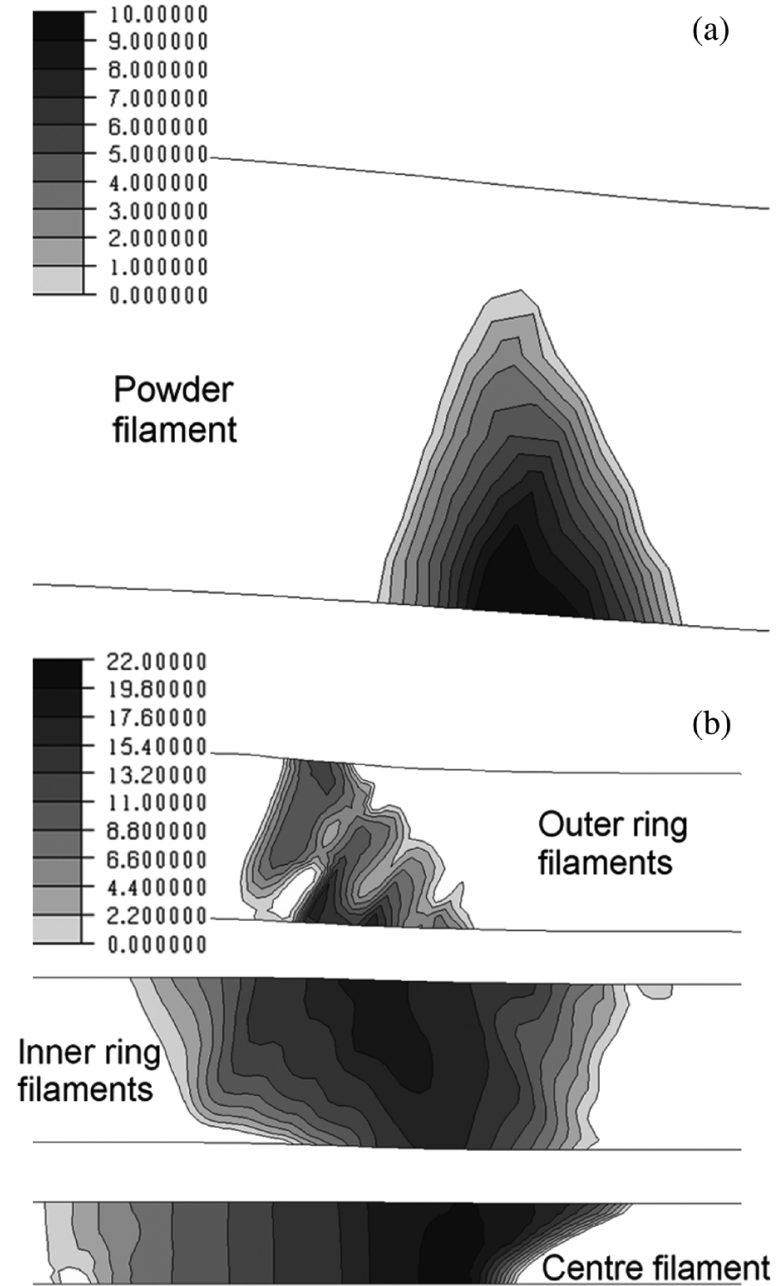

Fig. 9. Longitudinal section of axial stress (MPa) in powder during drawing: (a) 8-filament wire with copper core; (b) 19-filament wire. The center, inner ring and outer ring filaments corresponds to Fig. 7.

from the drawing of the single-filament. As such this material is vulnerable to fracture at high tensile stresses.

Fig. 9 shows the distribution of tensile stress in the axial direction for the powder filaments in the 8- and 19-filament wires for the final reduction step. White areas indicate zero tensile stress or compressive stresses in the axial direction. It is clearly seen that the tensile stresses in the powder of the 19-filament wire are larger than in the 8-filament wire by approximately a factor of two. It is also seen that for the powder, the largest tensile stresses for both wires are to be found nearest the center. This observation compares well with literature [18], where it is well established that for a solid metal wire, the largest tensile stresses in drawing are to be found in the middle of the wire as it passes through the drawing die. As such, since part of the powder is located in the center of the 19-filament wire this powder is subjected to substantially larger tensile stresses than the powder in the 8-filament wire, which is located closer to the perimeter of the wire.

In Fig. 10 tensile stress in the axial direction for the matrix material of the single-filaments is shown. Again, it is seen that the stress level is the highest in the 19-filament wire closest to

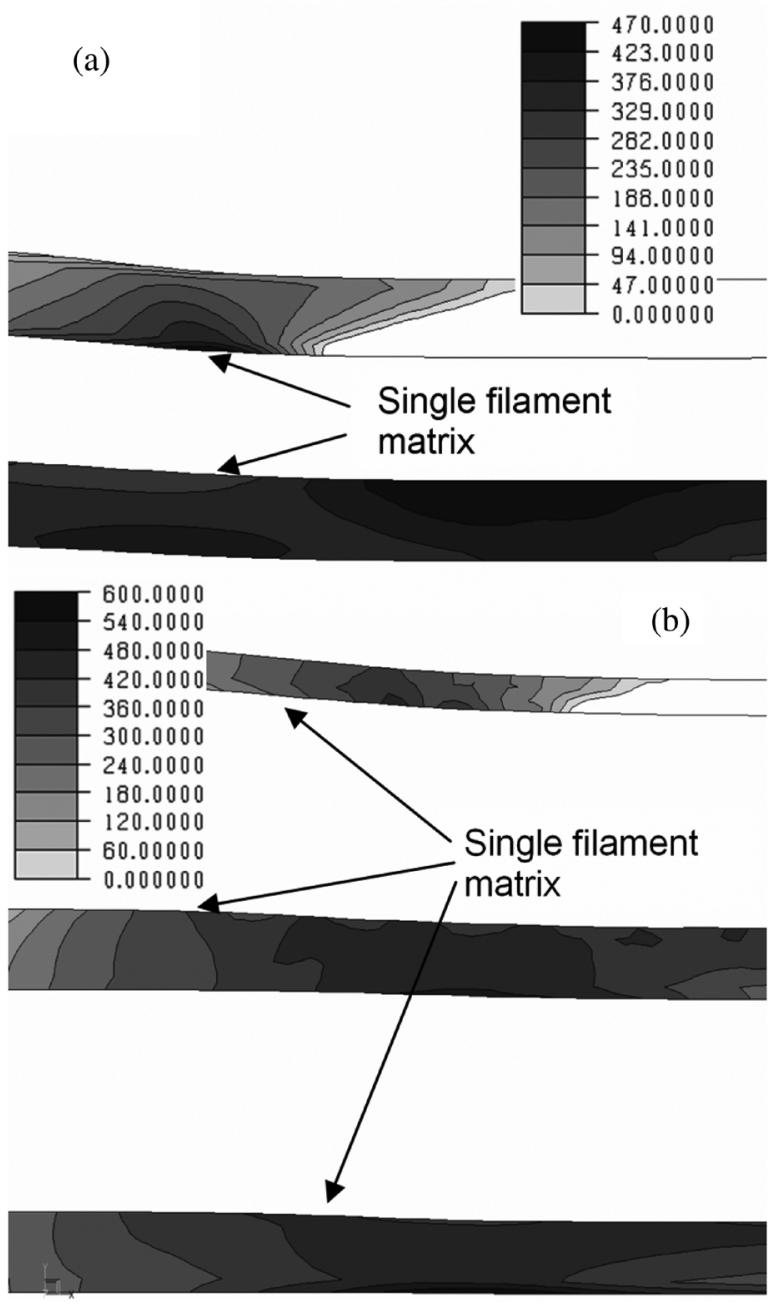

Fig. 10. Longitudinal section of axial stress (MPa) in matrix material of singlefilaments during drawing: (a) 8-filament wire with copper core; (b) 19-filament wire.

the center. This stress is larger than the maximum found in the 8 -filament wire by approximately $28 \%$.

Over all, the results from the numerical simulation support the experimental finding that the 8-filament wire is less sensitive to fracture. It also illustrates that this is due to the fact, that the critical components, namely the powder and the single-filament matrix material, are placed further from the center of the wire, where the largest tensile stresses are to be found.

\section{CONCLUSION}

It is clear from the present investigation that the addition of a copper core to a $\mathrm{Fe} / \mathrm{MgB}_{2}$ multifilament wire greatly reduces the need for annealing the Fe-matrix material. For ex-situ powder, annealing was required twice as often for the 19-filament wire without a copper core as compared to the 8 -filament wire with a copper core. Numerical simulation of the drawing process supports these findings, showing that axial stresses during drawing are concentrated around the middle of the wire. As such, careful planning of the packing strategy of multifilament wire can allow for sensitive components such as 
powder and pre-strained matrix material to be placed such that they experience a minimum of tensile stress during drawing.

It is also found that the multifilament wire containing in-situ powder required less annealing of the matrix material than was required for wire containing ex-situ powder, by approximately a factor of one half. The reason for this may be found in the fact that in-situ powder is more readily compacted than ex-situ powder.

\section{ACKNOWLEDGMENT}

The authors would like to thank Dr. Jean-Claude Grivel for his kind assistance with powder preparation and heat treatment of samples. Thanks also to M.Sc. Alvaro Pipo Benito for his work with drawing and rolling of wire and tape.

\section{REFERENCES}

[1] G. Grasso et al., "Fabrication and properties of monofilamentary MgB2 superconducting tapes," Supercond. Sci. Technol., vol. 16, pp. 271-275, 2003.

[2] G. Grasso et al., "Transport properties of powder-in-tube processed $\mathrm{MgB}_{2}$ tapes," Physica C, vol. 378-381, pp. 899-902, 2002.

[3] R. Flükiger, P. Lezza, C. Beneduce, N. Musolino, and H. L. Sou, "Improved transport critical current and irreversibility fields in mono- and multifilamentary Fe/MgB2 tapes and wires using fine powders," Supercond. Sci. Technol., vol. 16, pp. 264-270, 2003.

[4] R. Flükiger et al., "Superconducting properties of MgB2 tapes and wires," Physica C, vol. 385, pp. 286-305, 2003.
[5] D. Eyidi et al., "Superconducting properties, microstructure and chemical composition of $\mathrm{MgB}_{2}$ sheathed materials," Supercond. Sci. Technol., vol. 16, pp. 778-788, 2003.

[6] H. Kitaguchi, A. Matsumoto, H. Hatakeyama, and H. Kumakura, "High temperature performance of $\mathrm{MgB}_{2}$ powder-in-tube composite tapes," Supercond. Sci. Technol., vol. 16, pp. 26-30, 2003.

[7] Y. Ma, H. Kumakura, A. Matsumoto, H. Hatakeyama, and K. Togano, "Improvement of critical current density in Fe-sheathed $\mathrm{MgB}_{2}$ tapes by $\mathrm{ZrSi}_{2}, \mathrm{ZrB}_{2}$ and $\mathrm{WSi}_{2}$ doping," Supercond. Sci. Technol., vol. 16, pp. 852-856, 2003.

[8] B. A. Glowacki et al., "Composite $\mathrm{Cu} / \mathrm{Fe} / \mathrm{MgB}$, superconducting wires and $\mathrm{MgB}_{2} / \mathrm{YSZ} / \mathrm{Hastelloy}$ coated conductors for ac and $\mathrm{dc}$ applications," Supercond. Sci. Technol., vol. 16, pp. 297-305, 2003

[9] B. A. Glowacki et al., " $\mathrm{MgB}_{2}$ superconductors for applications," Physica C, vol. 387, pp. 153-161, 2003.

[10] E. W. Collings et al., "Continuous- and batch-processed $\mathrm{MgB}_{2} / \mathrm{Fe}$ strands-Transport and magnetic properties," Physica C, vol. 386, pp. 555-559, 2003.

[11] S. Soltanian et al., "High-transport critical current density above $30 \mathrm{~K}$ in pure Fe-clad $\mathrm{MgB}_{2}$ tape," Physica $C$, vol. 361, pp. 84-90, 2001.

[12] S. Soltanian et al., "Fabrication and critical current density in 16-filament stainless steel/Fe/ $\mathrm{MgB}_{2}$ square wire," Solid State Commun., vol. 124, pp. 59-62, 2002.

[13] B. A. Glowacki and M. Majoros, “ $\mathrm{MgB}_{2}$ conductors for dc and ac applications," Physica C, vol. 327, pp. 1235-1240, 2002.

[14] R. Musenich et al., "Behavior of $\mathrm{MgB}_{2}$ react \& wind coils above 10 K," IEEE Trans. Appl. Supercond., vol. 15, pp. 1452-1456, 2005.

[15] M. D. Sumption et al., "Multifilamentary, in situ route, Cu-stabilized $\mathrm{MgB}_{2}$ strands," Supercond. Sci. Technol., vol. 18, pp. 730-734, 2005.

[16] S. Kalpakjian, Manufacturing Engineering and Technology, 3rd ed. : Addison-Wesley Publishing Co., 1995.

[17] M. S. Nielsen, N. Bay, M. Eriksen, J. I. Bech, and M. H. Hancock, "An alternative to the conventional triaxial compression test," Powder Technology, vol. 161, pp. 220-226, 2006.

[18] B. Avitzur, Handbook of Metal-Forming Processes. New York: John Wiley and Sons, Inc, 1983. 